\title{
Possible Involvement of Nuclear Factor Kappa $B$ in Rapid Disease Progression in ART Naive HIV-1 Infected Remunerated Blood Donors with History of Oral Iron Intake
}

\author{
Debasish Chattopadhya1,2 \\ ${ }^{1}$ Center for AIDS and Related Diseases, National Center for Disease Control, Delhi, India \\ ${ }^{2}$ Department of Microbiology, Faculty of Medicine and Health Sciences, SGT University, Gurgaon, India \\ Email: dchattopadhya27@gmail.com
}

How to cite this paper: Chattopadhya, D. (2018) Possible Involvement of Nuclear Factor Kappa B in Rapid Disease Progression in ART Naive HIV-1 Infected Remunerated Blood Donors with History of Oral Iron Intake. Journal of Biosciences and Medicines, 6, 66-76.

https://doi.org/10.4236/jbm.2018.67006

Received: June 25, 2018

Accepted: July 24, 2018

Published: July 27, 2018

Copyright $\odot 2018$ by author and Scientific Research Publishing Inc. This work is licensed under the Creative Commons Attribution International License (CC BY 4.0).

http://creativecommons.org/licenses/by/4.0/

\begin{abstract}
A retrospective analysis on the assessment of the level of $\mathrm{p} 65$ component of the transcription factor Nuclear Factor Kappa B (NF-kB p65) in the nuclear extract of lipopolysaccharide stimulated peripheral blood mononuclear cells (PBMCs) of remunerated blood donors with HIV-1 infection revealed NF-kB p65 level to be significantly higher in the subgroup with history of oral iron intake compared to the HIV-1 infected subgroup without such history. The level of NF-kB p65 in iron consuming subgroup of HIV-1 positive donors showed positive correlation with the serum ferritin level and with the rate of increase in viral load. The NF-kB $\mathrm{p} 65$ level also showed positive correlation with the level of superoxide produced by cultured Monocyte derived macrophages (MDMs) as well as with the levels of the immune activation markers viz. Tumour necrosis factor alpha (TNF- $\alpha$ ) and two of its soluble markers i.e. Tumour necrosis factor receptor types one and two (TNFRI and TNFRII) reported in earlier studies in the same subgroup. The opposing roles of NF-kB in situation of iron overload in HIV-1 infection i.e. disease enhancement on one hand and facilitation of effective antiretroviral therapy through activation of HIV-1 in the latently infected cells on other hand suggest the need for further research to weigh benefits and risks of iron therapy in situations where iron deficiency in HIV-1 infection may be a serious consideration.
\end{abstract}

\section{Keywords}

NF-kB p65, Viral Load, Immune Activation Markers, Iron Overload 


\section{Introduction}

There are numerous reports indicating enhancing effect of iron on disease progression in Human Immunodeficiency Virus type-1 (HIV-1) infection [1] [2] [3]. In one of our previous study on an asymptomatic group of remunerated blood donors at early stage of HIV-1 infection, it was found that the subgroup with history of oral iron intake and biochemical evidence of serum iron overload had significantly faster disease progression with development of high incidence of pulmonary tuberculosis on follow up compared to the similar subgroup but without any history of iron intake [4]. However, at the same time, in the second part of documentation on the same subgroups of donors highlighting different set of investigations, iron consuming subgroup demonstrated high level of superoxide production by cultured monocyte derived macrophages (MDMs) [5] that was an apparently paradoxical observation since superoxide anion is considered an important bactericidal tool of macrophages against Mycobacterium tuberculosis (M.tb). Various reactive oxygen species (ROS) including superoxide facilitate multiplication of HIV-1 via activation of the transcription factor viz. nuclear factor kappa B (NF-kB), of which the main $65 \mathrm{kDa}$ transactivation domain, i.e. NF- $\mathrm{BB}$ p 65 or RelA migrates (translocates) to nucleus on activation where it plays a pivotal role in transactivation of viral genes, including that of HIV-1 [6] [7]. Thus it may be possible that any potentially beneficial bactericidal effect of superoxide against M.tb is offset by its contribution in multiplication of HIV-1 in high iron status. Further, in the first part of the report, the iron consuming subgroup of HIV-1 positive donors showed high state of immune activation as evident from elevated serum levels of Tumor Necrosis Factor alpha (TNF- $\alpha$ ) and two of its receptors viz. TNFRI (p55) and TNFRII (p75) although the probable mechanism for such high immune activation was not explored [4]. The present report provides retrospective analysis of NF- $\mathrm{B}$ p65 level in nuclear extracts of peripheral blood mononuclear cells (PBMCs) stimulated by Lipopolysaccharide (LPS) in the subgroups of asymptomatic HIV-1 positive blood donor with history of oral iron intake, in relation to reported levels of serum ferritin, rate of increase in HIV-1 viral load, superoxide produced by MDM culture and serum levels of the three immune activation markers viz. TNF- $\alpha$, TNFRI and TNFRII [4] [5].

\section{Materials and Methods}

\subsection{Study Subjects and Protocol of the Study}

The present report includes a total of $118 \mathrm{HIV}-1$ seropositive remunerated blood donors comprising of 60 with and 58 without history of iron intake (Subgroups I and II respectively) enrolled in our earlier study with the demographic and epidemiological characteristics described in the same study [4]. Briefly the subjects, seropositive for HIV-1 infection by screening ELISA and confirmatory western blot, were at their initial asymptomatic stage of HIV-1 infection as evident by duration of infection and unimpaired peripheral CD4 lymphocyte counts (i.e. > 
500/cu $\mathrm{mm}$ ) and did not have serological evidence of co-infections by Hepatitis B virus (HBV), Hepatitis C virus (HCV) and Syphilis. The enrolled blood donors were subjected to estimation of NF-kB p65 in nuclear extracts of LPS stimulated PBMCs at enrolment, details of which previously unreported, is presented in the present report. Further, the NF-kB p65 level in PBMC nuclear extract was assessed in iron consuming subgroup of donors in relation to serum levels of ferritin and immune activation markers i.e. TNF- $\alpha$, TNFRI and TNFRI as well as superoxide production by cultured MDMs observed earlier on the same group of donors [4] [5]. The present report also analyses correlation between NF-kB p65 level in nuclear extract of LPS stimulated PBMCs with the pattern of changes in viral load following viral set point in Subgroup I, not reported in our previous studies. Data on 40 healthy non-donor community controls included in the previous two studies [4] [5] are included for analysis.

\subsection{Estimation of NF-кB p65 in Nuclear Extract of LPS Stimulated PBMC Culture}

\subsubsection{Isolation of PBMCs}

About $6 \mathrm{ml}$ of blood collected in EDTA was centrifuged at $1000 \mathrm{~g} \times 20$ minutes to obtain cellular fraction in the pellet. The supernatant representing the plasma was removed gently and the pellet representing the cellular fraction was suspended in equal volume of phosphate buffered saline (PBS, pH 7.4), mixed with wide mouth pipette and gently layered on Ficoll-hypaque (sp.gr 1.007) followed by centrifugation at $1200 \mathrm{~g}$ for 20 minutes. The buffy coat, rich in PBMCs, was washed 3 times in isotonic PBS. The PBMC suspension was found to contain $>95 \%$ of viable cells by trypan blue exclusion method and $>97 \%$ pure PBMCs by flow cytometric analysis using monoclonal anti-CD3, anti-CD19 and anti-CD14 antibodies. The PBMC suspension was adjusted to $\sim 1 \times 10^{6}$ cells $/ \mathrm{ml}$.

\subsubsection{Estimation of NF- $\mathrm{KB}$ p65 in Nuclear Extracts of LPS Stimulated PBMCs}

This was carried out following broadly the original protocol by Zheng et al. [8] with minor modifications adapted by $\mathrm{Yu}$ et al. [9]. The protocol involved three steps viz. 1) treatment of PBMCs with mitogen LPS to induce translocation of NF-kB p65 from cytoplasm into the nucleus 2) extraction of nuclear proteins from LPS stimulated PBMCs 3) estimation of NF-kB p65 in nuclear protein extracts of LPS stimulated PBMCs.

1) Treatment of PBMCs with LPS: Three ml of PBMC suspension $\left(\sim 3 \times 10^{6}\right.$ cells) was subjected to treatment with LPS (derived from Escherichia coli, serotype 0111:B4, Sigma chemicals, USA), $10 \mathrm{ng} / \mathrm{ml}$ for 10 minutes of incubation at $37^{\circ} \mathrm{C}$ in a humidified $\mathrm{CO}_{2}$ chamber to facilitate translocation of NF-kB p65 from cytoplasm into nucleus. One $\mathrm{ml}$ of PBMC suspension $\left(\sim 1 \times 10^{6}\right.$ cells $)$ was included without any mitogen treatment as control and incubated under identical condition.

2) Extraction of nuclear proteins from LPS stimulated PBMC nuclei: This 
procedure was carried out in presence of protease inhibitor cocktail to prevent loss of extracted protein.

a) Reagents used:

The reagents for extraction of proteins viz. Nonidet P-40, HEPES, DTT (DL-Dithiothreitol), $\mathrm{MgCl}_{2}, \mathrm{KCL}$, Tris-HCl, Na-EDTA and Glycerol were all procured from local supplier (Hi-Media Laboratories, India). The reagents for preparation of protease inhibitor cocktail as per concentrations mentioned were all procured from a different source (Sigma chemicals USA) viz. Phenyl-methyl-sulfonyl fluoride (PMSF) (Cat No P7626) $0.5 \mathrm{mM}$, Leupeptine (Cat No L8511) $1 \mathrm{mg} / \mathrm{ml}$, Pepstatin (Cat No P 4625) $0.5 \mathrm{mg} / \mathrm{ml}$, Aprotinin (Cat No A1153) $1 \mathrm{mg} / \mathrm{ml}$, EGTA (Cat No E8145) $1 \mathrm{mM}$, Sodium orthovanadate $\left(\mathrm{Na}_{3} \mathrm{VO}_{4}\right.$, Cat No S6508) $1 \mathrm{mM}$. PMSF was prepared fresh each time before use.

b) Extraction of nuclear protein from LPS stimulated and unstimulated (control) PBMCs:

LPS treated PBMC suspension was centrifuged at $750 \mathrm{~g}$ at $4^{\circ} \mathrm{C}$. The pellet was washed twice with cold HEPES buffer followed by suspension in $20-40 \mu \mathrm{l}$ ice cold hypotonic HEPES buffer composed of HEPES (10 mM, pH 7.8), $\mathrm{MgCl}_{2}(1.5$ $\mathrm{mM}), \mathrm{KCL}(10 \mathrm{mM})$, DTT $(0.5 \mathrm{mM})$ containing $0.1 \%$ Nonidet P- 40 . The suspension was kept on ice for 10 minutes followed by centrifugation at 10,000 $\mathrm{g}$ for 10 minutes. The supernatant was designated as cytoplasmic fraction. The pellet representing nuclear fraction was re-suspended in $35-40 \mu \mathrm{l}$ ice cold high salt buffer (20 mM HEPES pH 7.9, $420 \mathrm{mM} \mathrm{NaCl}, 1.5 \mathrm{mM} \mathrm{MgCl} 2,0.2 \mathrm{mM}$ EDTA and $25 \%$ Glycerol) containing $10 \mu \mathrm{l}$ of protease inhibitor cocktail, followed by incubation at $4^{\circ} \mathrm{C}$ for 15 minutes with intermittent shaking. The suspension containing lysed nuclei was vortexed and centrifuged at $10,000 \mathrm{~g}$ at $4^{\circ} \mathrm{C}$ for 10 minutes for settling the nuclear debris. The supernatant representing the nuclear extract was collected and stored at $-80^{\circ} \mathrm{C}$ with addition of $75-100 \mu$ of HEPES buffer ( $\mathrm{pH}$ 7.9).

The protein concentration of the extract was determined by Bradford's method in 96-well microplate using Coomassie dye reagent with bovine serum albumin as calibration standards [10]. The concentration of protein in nuclear extract suspension was adjusted to $100 \mu \mathrm{g} / \mathrm{ml}$.

3) Estimation of NF-kB p65 in nuclear fraction: This procedure was carried out by commercial ELISA kit as per manufacturer's protocol (Cusabio, Wuhan, China; sensitivity $0.078 \mathrm{ng} / \mathrm{ml}$, intra-assay and inter-assay coefficient of variation $<10 \%)$. Briefly, $100 \mu \mathrm{l}(10 \mu \mathrm{g})$ of nuclear protein extracts in triplicate and $100 \mu \mathrm{l}$ of dilutions of standards (supplied with the kit) were charged in the ELISA plate wells coated with monoclonal anti-NF-kB p65 antibody followed by incubation at $37^{\circ} \mathrm{C}$ for $2 \mathrm{hr}$. The liquid was aspirated from the wells and $100 \mu \mathrm{l}$ of biotin-conjugated anti-NF-kB p65 antibody was added to each well. The plate was incubated at $37^{\circ} \mathrm{C}$ for $1 \mathrm{hr}$ followed by washing 3 times. One hundred microliter of HRP-avidin conjugate was added onto the wells and the plate was incubated at $37^{\circ} \mathrm{C}$ for $1 \mathrm{hr}$.The plate was then washed 5 times. Ninety microliter of TMB 
was added and incubated at $37^{\circ} \mathrm{C}$ for 15 - 30 minutes in dark followed by addition of $100 \mu \mathrm{l}$ of $0.18 \mathrm{M} \mathrm{H}_{2} \mathrm{SO}_{4}$ as stop solution. The plate was read at $450 \mathrm{~nm}$ with correction at wavelength of $540 \mathrm{~nm}$. Concentration of NF-kB p65 in the nuclear extract was expressed as nanogram (ng) of NF-kB p65 per microgram $(\mu \mathrm{g})$ of nuclear protein extract after taking the average of three wells [11].

\section{Statistical Analysis}

Statistical analysis was carried out by Stata, version 11 (Stata-Corp., 2010). Comparison of levels of NF-kB p65 in PBMC Nuclear extracts in subgroup I, subgroup II and controls was carried out by student's t test, with ANOVA performed for overall comparison. The correlation between laboratory parameters was evaluated by Spearman's rank coefficient. Linear regression analysis was used to assess the relationship between the laboratory parameters.

\section{Results}

The level of NF-kB p65 in LPS stimulated PBMC nuclear extract, expressed as nanogram per microgram of protein in nuclear extract, was significantly higher with mean and standard deviation as 4.01 and 1.07 respectively in the subgroup of HIV-1 positive blood donors with history of oral iron intake (i.e. subgroup I) compared to the subgroup without any such history (subgroup II) with mean and standard deviation as 1.02 and 0.43 respectively $(p<0.001)$. The corresponding level of NF-kB p65 in the healthy control group was much lower compared to both the subgroups of HIV-1 positive donors $(p<0.001)$ with mean and standard deviation as 0.48 and 0.08 (Figure 1). The level of NF-kB p65 in

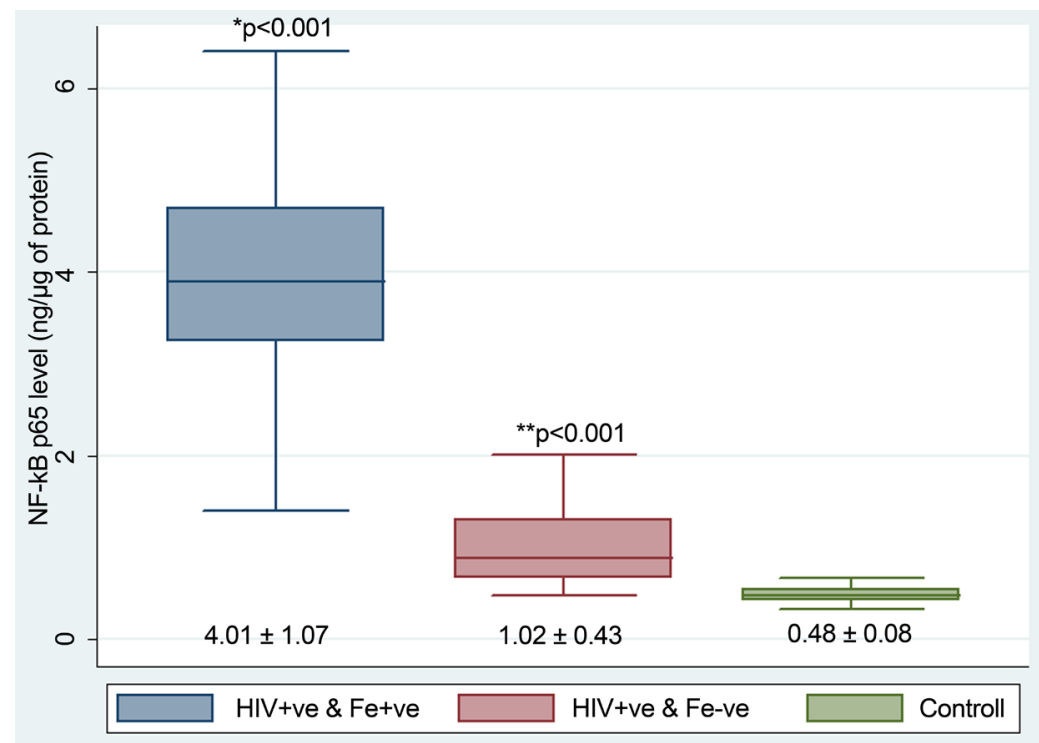

Figure 1. Box plot showing levels of NF-kB p65 in PBMC derived nuclear extracts in the two subgroups of HIV-1 infected blood donors with and without history of oral iron intake (indicated as $\mathrm{HIV}+\& \mathrm{Fe}+$ and $\mathrm{HIV}+\& \mathrm{Fe}-$ respectively) as well as in controls. * symbolizes significant difference compared to subgroup II as well as to controls while ${ }^{\star \star}$ symbolizes significant difference compared to controls. 
subgroup I donors showed positive correlation with the serum ferritin level (mean $\pm \mathrm{SD}$ as $328 \pm 136 \mu \mathrm{g} / \mathrm{L}$ ) (Figure 2) and with the rate of increase (per month) in HIV-1 viral load over 6 months following viral set point (mean \pm SD of $\log _{10}$ HIV-1 viral load at viral set point as $4.35 \pm 0.68$ ) (Figure 3 ). The NF-kB p65 level also showed positive correlation with the level of superoxide produced by recombinant human gamma interferon ( $\operatorname{rhIFN}-\gamma$ ) primed MDM culture (mean $\pm \mathrm{SD}$ as $17.67 \pm 4.97 \mathrm{nmol} / \mathrm{mg}$ protein/min) (Figure 4) as well as with the levels of all the three immune activation markers i.e. TNF- $\alpha$ (mean \pm SD as 24.6 $\pm 10.5 \mathrm{pg} / \mathrm{ml}$ ),TNFRI (mean \pm SD as $3.8 \pm 2.5 \mathrm{ng} / \mathrm{ml}$ ) and TNFRII (mean $\pm \mathrm{SD}$ as $10.2 \pm 3.8 \mathrm{ng} / \mathrm{ml}$ ) (Figures $5(\mathrm{a})-(\mathrm{c})$ ).

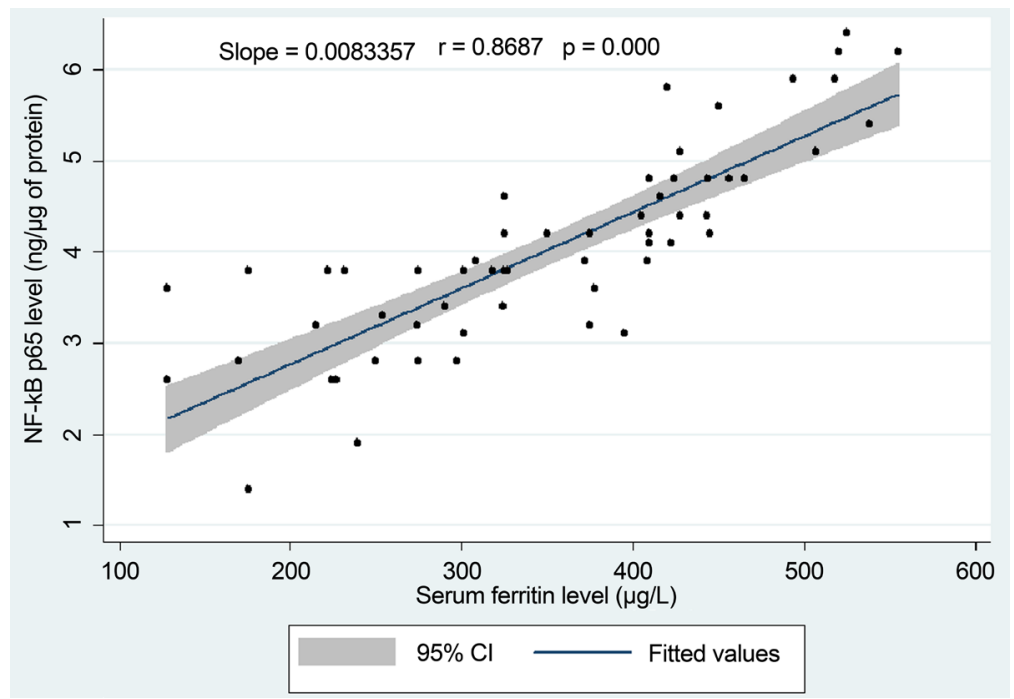

Figure 2. Correlation between serum ferritin level and PBMC derived NF-kB p65 level in the subgroup of HIV-1 infected blood donors with history of oral iron intake.

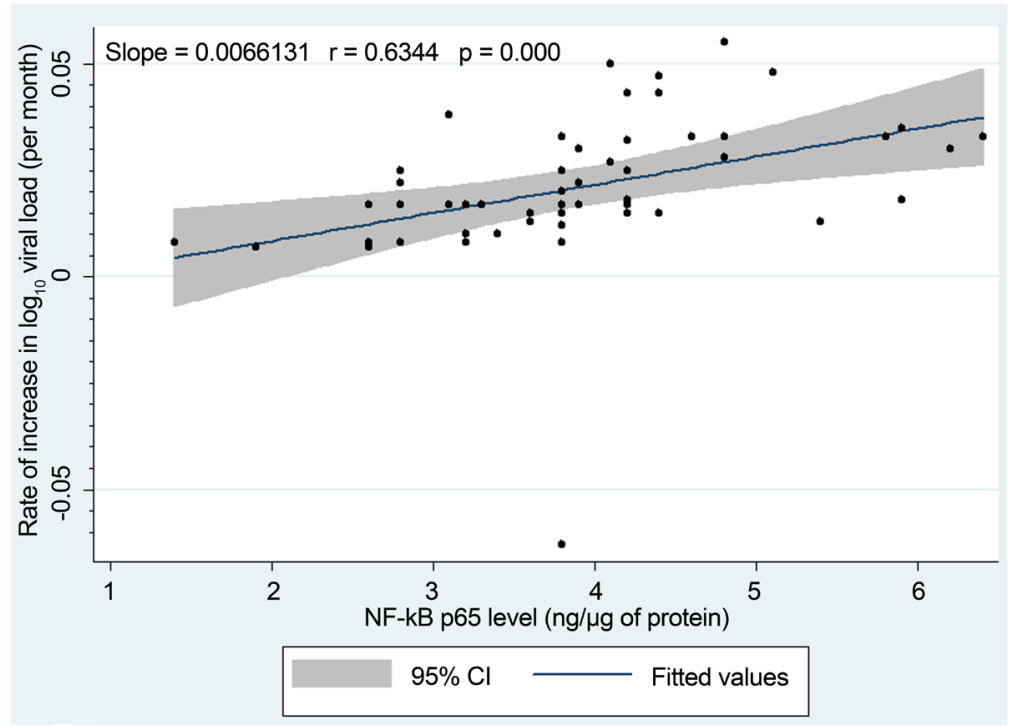

Figure 3. Correlation between PBMC derived NF-kB p65 level and rate of increase in viral load during 6 months period following viral set point in the subgroup of HIV-1 infected blood donors with history of oral iron intake. 


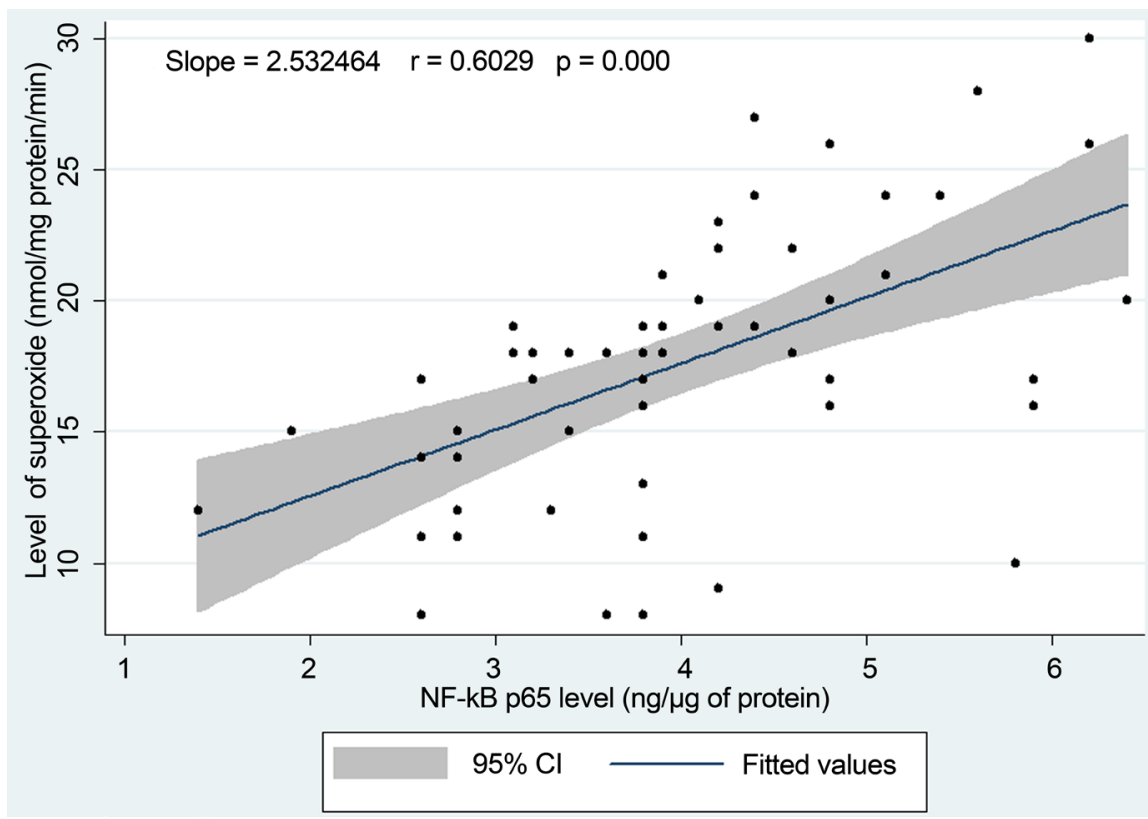

Figure 4. Correlation between PBMC derived NF-kB p65 level and quantity of superoxide produced by MDM culture in the subgroup of HIV-1 infected blood donors with history of oral iron intake.

\section{Discussion}

Effect of iron on enhancement of disease progression in HIV-1 infection has been substantially established (reviewed by Gordeuk et al. [2] [12]). They are broadly based on several observations. First, in HIV-1 positive thalassemia major patients, the rate of progression of HIV disease was significantly faster in patients with lower doses of desferrioxamine and higher serum ferritin concentrations. Second, the inadvertent simultaneous administration of low doses of oral iron with dapsone for the prophylaxis of Pneumocystis carinii (now known as Pneumocystis jiroveci) pneumonia in HIV-positive patients may have been associated with excess mortality. Third, study of haptoglobin polymorphisms in HIV-positive subjects indicated that the haptoglobin 2-2 polymorphism is associated with higher iron stores and shortened survival as compared with the haptoglobin 1-1 or 2-1 phenotypes. Fourth, retrospective study of bone marrow macrophage iron in HIV-positive patients suggested that survival is shorter with high iron stores. Additional evidence suggesting iron overload as a risk factor for rapid progression of the disease includes slowing down of the disease course following iron chelation therapy in HIV-positive patients with thalassemia major [13].

The progression of HIV-1 infection correlates closely with the replication efficiency of the virus [14]. Replication of HIV-1 in turn is coupled with the transcription of the viral genome that is initiated from the long-term repeat (LTR) region of the viral genome containing adjacent NF-kB binding sites [15]. This was further supported by the observation that mutants of IkBa that block NF-kB induction also inhibit HIV-1 infection in T cells by interfering with viral 


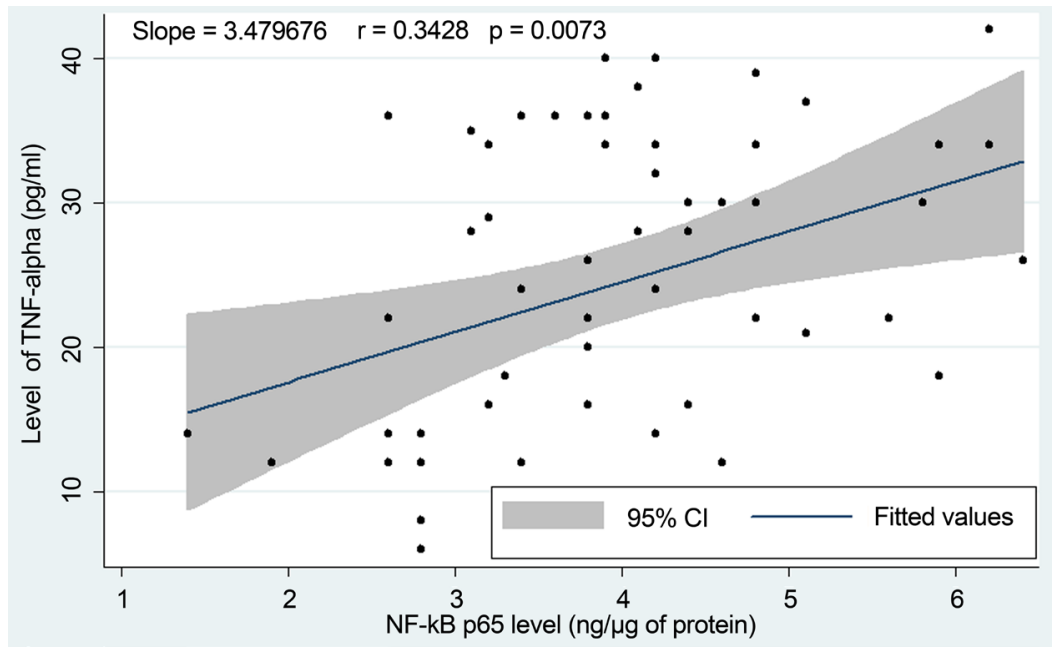

(a)

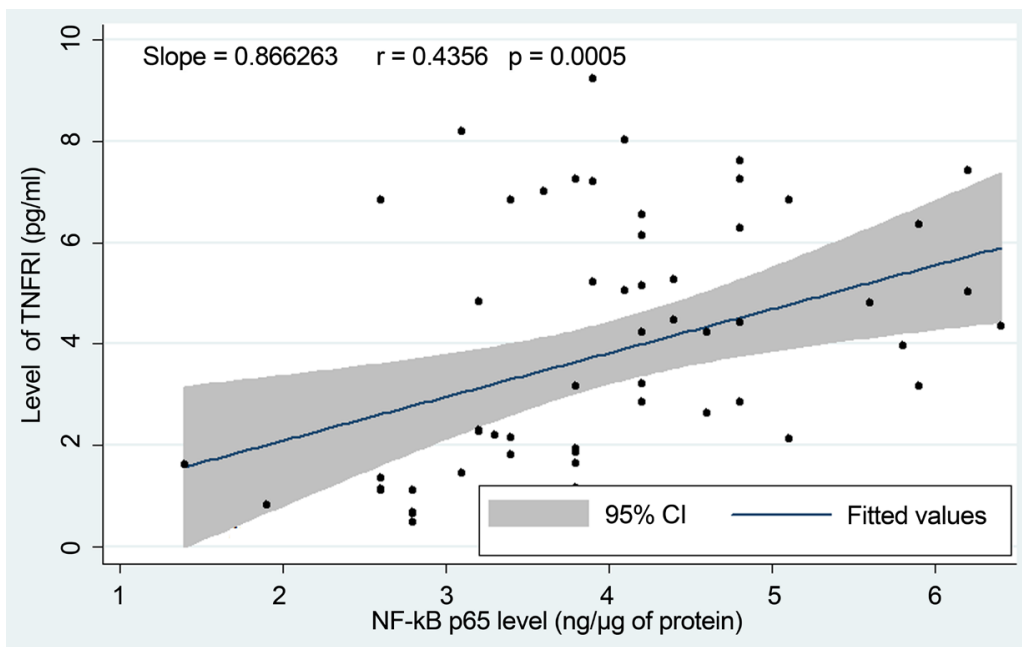

(b)

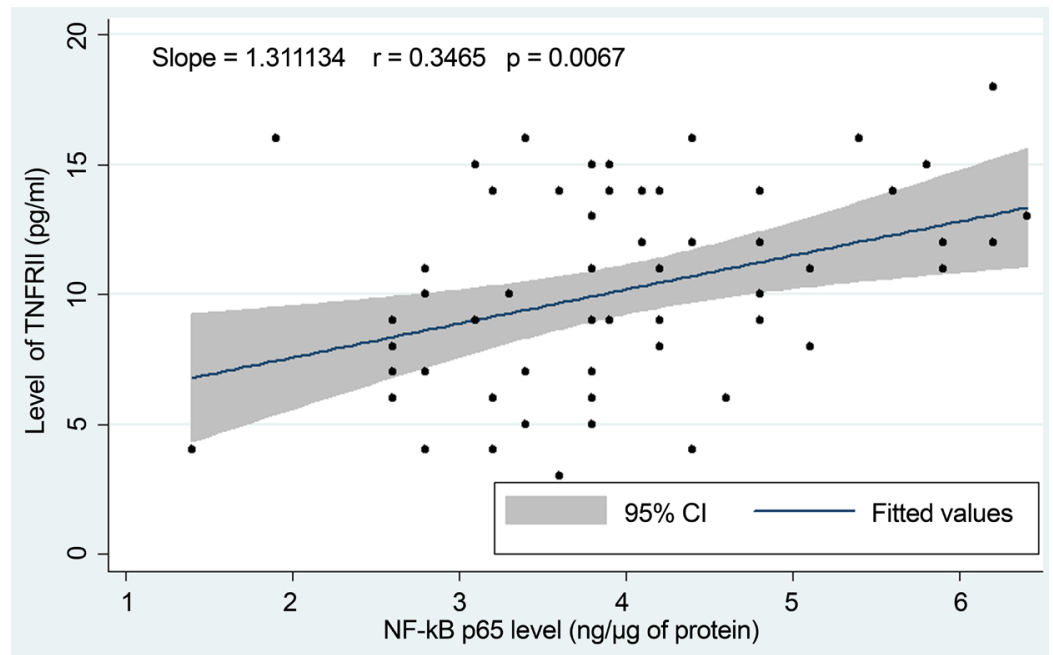

(c)

Figure 5. Correlations between PBMC derived NF-kB p65 levels and serum levels of (a) TNF- $\alpha$, (b) TNF RI and (c) TNF RII in the subgroup of HIV-1 infected blood donors with history of oral iron intake. 
transcription [16]. The transcriptional activity of LTR region is dependent on the number of NF-kB binding sites. The LTR from HIV-1 subtype C, the predominant subtype in India [17] contains three NF-kB binding sites [18]. Activation of NF-kB by iron is an important element in the life cycle of HIV-1 [3]. In addition, reverse transcription of HIV RNA into DNA by the enzyme reverse transcriptase requires the iron dependent protein Ribonucleotide Reductase [19]. In cultured cells, excess of iron is associated with an increased HIV-1 viral replication while iron chelators inhibit HIV-1 transcription [20]. Thus, elevated level of NF-kB p65 in stimulated PBMC observed in the iron consuming subgroup of blood donors with its level showing positive correlations with serum ferritin level and with rate of increase in plasma viral load substantiates the possible interrelationship between iron overload and disease progression in HIV-1 infected blood donors reported earlier [4].

High level generation of reactive oxygen species (ROS) including superoxide has been reported in situations of iron overload e.g. in thalassemia children [21] which support the high superoxide production by MDMs reported earlier in the iron consuming subgroup [5]. Reactive oxygen species (ROS) are known to be potent stimulators of NF-kB [22] raising the possibility of an alternate or additional pathway of high viral replication in high iron state that is reflected by the positive correlation between level of NF-kB p65 in the present report and superoxide level in cultured MDMs reported in the earlier study.

Macrophage is the largest producer of TNF- $\alpha$ [23]. High iron level has not been reported to influence TNF- $\alpha$ production by macrophages. In fact, the mean concentrations of immunoreactive tumor necrosis factor-alpha (TNF-alpha) in the supernatants were recorded to be lower in the hereditary hemochromatosis patients compared to healthy controls [24]. Thus it is more likely that increased levels of TNF- $\alpha$, TNFRI and TNFRII encountered in iron consuming blood donors are mediated by $\mathrm{NF}-\mathrm{kB}$ as evident by the positive correlation between NF-kB p65 level and the levels of three immune activation markers [25].

Persistence of a latent pool of HIV-1 provirus poses a barrier for effective anti-retroviral therapy as integrated HIV-1 is not affected by the anti-retroviral drugs until viral transcription is activated [26]. From this point of view, iron with its role of activating NF-kB, should be a beneficial adjunct towards effective antiretroviral therapy. At the same time, numerous possible adverse outcomes of HIV-1 infection due to iron overload reported so far are likely to outweigh such benefit. Therefore, further research is needed to judge merits and demerits of oral iron therapy that is not uncommonly considered for treatment of anemia in HIV-1 infection.

\section{Acknowledgements}

The author is thankful to Dr Onkar Swami, Ex-Ph.D scholar, University of Delhi for his help in the graphs and Dr Alice Verghese of NCDC for valuable suggestions. 


\section{References}

[1] Nekhai, S., Kumari, N. and Dhawan, S. (2013) Role of Cellular Iron and Oxygen in the Regulation of HIV-1 Infection. Future Virology, 8, 301-311.

https://doi.org/10.2217/fvl.13.6

[2] Gordeuk, V.R., Delanghe, J.R., Langlois, M.R. and Boelaert, J.R. (2001) Iron Status and the Outcome of HIV Infection: An Overview. Journal of Clinical Virology, 20, 111-115. https://doi.org/10.1016/S1386-6532(00)00134-7

[3] Drakesmith, H. and Prentice, A. (2008) Viral Infection and Iron Metabolism. Nature Reviews Microbiology, 6, 541-552. https://doi.org/10.1038/nrmicro1930

[4] Chattopadhya, D. and Baveja, U. (2018) High Incidence of Pulmonary Tuberculosis in ART Naive Remunerated Blood Donors with Human Immunodeficiency Virus Type-1 Infection: Possible Role of Iron Overload. Journal of Biosciences and Medicines, 6, 62-82. https://doi.org/10.4236/jbm.2018.62006

[5] Chattopadhya, D. and Verghese, A. (2018) Impaired in Vitro Macrophage Function in HIV-1 Infected Remunerated Blood Donors with History of Oral on Intake. Journal of Biosciences and Medicines, 6, 1-24.

[6] Ghose, S. and Karin, M. (2002) Missing Pieces in the NF-Kappa B Puzzle. Cell, 109, S81-S96.

[7] Stroud, J.C., Oltman, A., Han, A., Bates, D.L. and Chen, L. (2009) Structural Basis of HIV-1 Activation by NF- $\kappa$ B-A Higher-Order Complex of p50: RelA Bound to the HIV-1 LTR. Journal of Molecular Biology, 393, 98-112. https://doi.org/10.1016/j.jmb.2009.08.023

[8] Zheng, S., Brown, M.C. and Taffet, S.M. (1993) Lipopolysaccharide Stimulates Both Nuclear Localization of the Nuclear Factor kB 50-kDa Subunit and Loss of the $105-\mathrm{kDa}$ Precursor in RAW264 Macrophage-Like Cells. The Journal of Biological Chemistry, 268, 17233-17239.

[9] Yu, X.-P., Bellido, T. and Manolagas, S.C. (1995) Down Regulation of NF-Kappa B Protein Levels in Activated Human Lymphocytes by 1,25-Dihydroxy-Vitamin D3. PNAS (USA), 92, 10990-10994. https://doi.org/10.1073/pnas.92.24.10990

[10] Bradford, M.H. (1976) A Rapid and Sensitive Method for the Quantitation of Microgram Quantities of Protein Utilizing the Principle of Protein-Dye Binding. Analytical Biochemistry, 72, 248-254. https://doi.org/10.1016/0003-2697(76)90527-3

[11] Garbin, U., Pasini, A.F., Stranieri, C., Cominacini, M., Pasini, A., Manfro, S., et al. (2009) Cigarette Smoking Blocks the Protective Expression of Nrf2/ARE Pathway in Peripheral Mononuclear Cells of Young Heavy Smokers Favoring Inflammation. PLOS ONE, 4, e8225.

[12] Banjoko, S.O., Osemi, F.A., Togun, R.A., Onayemi, O., Emma-Okon, B.O. and Fakunie, J.B. (2012) Iron Status in HIV-1 Infection: Implications in Disease Pathology. BMC Clinical Pathology, 12, 26-31.

[13] Salhi, Y., Costagliola, D., Rebulla, P., Dessi, C., Karagliorga, M., Lena-Russo, D., et al. (1998) Serum Ferritin, Desferrioxamine, and Evolution of HIV-1 Infection in Thalassemic Patients. Journal of Acquired Immune Deficiency Syndromes \& $\mathrm{Hu}$ man Retrovirology, 18, 473-478. https://doi.org/10.1097/00042560-199808150-00009

[14] Selhorst, P., Combrink, C., Ndabambi, N., Ismail, S.D., Abrahams, M.R., Lacarda, M., et al. (2017) Replication Capacity of Viruses from Acute Infection Drives HIV-1 Disease Progression. Journal of Virology, 91, e01806-e01816. https://doi.org/10.1128/JVI.01806-16 
[15] West, M.J., Lowe, A.D. and Karn, J. (2001) Activation of Human Immunodeficiency Virus Transcription in T Cells Revisited: NF- $\kappa$ B p65 Stimulates Transcriptional Elongation. Journal of Virology, 75, 8524-8537. https://doi.org/10.1128/JVI.75.18.8524-8537.2001

[16] Kwon, H., Pelletier, N., DeLuca, C., Genin, P., Cisterna, S., Lin, R., et al. (1998) Inducible Expression of $\mathrm{I} \kappa \mathrm{B} \alpha$ Repressor Mutants Interferes with NF- $\kappa \mathrm{B}$ Activity and HIV-1 Replication in Jurkat T Cells. The Journal of Biological Chemistry, 273, 7431-7440. https://doi.org/10.1074/jbc.273.13.7431

[17] Neogi, U., Bontell, I., Shet, A., De Costa, A., Gupta, S., Diwan, V., et al. (2012) Molecular Epidemiology of HIV-1 Subtypes in India: Origin and Evolutionary History of the Predominant Subtype C. PLoS ONE, 7, e39819. https://doi.org/10.1371/journal.pone.0039819

[18] Jeeninga, R.E., Hoogenkamp, M., Amand-Ugon, M., de Baar, M., Verhoef, K. and Berkhout, B. (2000) Functional Differences between the Long Terminal Repeat Transcriptional Promoters of Human Immunodeficiency Virus Type-1 Subtypes A through G. Journal of Virology, 74, 3740-3751. https://doi.org/10.1128/JVI.74.8.3740-3751.2000

[19] Zhang, C., Liu, G. and Huang, M. (2014) Ribonucleotide Reductase Metallocofactor: Assembly, Maintenance and Inhibition. Frontiers in Biology, 9, 104-113. https://doi.org/10.1007/s11515-014-1302-6

[20] Traore, H.N. and Meyer, D. (2004) The Effect of Iron Overload on in Vitro HIV-1 Infection. Journal of Clinical Virology, 31, 92-98. https://doi.org/10.1016/j.jcv.2004.09.011

[21] Porter, J.B., de Witte, E., Cappellini, M.D. and Gattermann, N. (2016) New Insights into Transfusion Related Toxicity: Implication for the Oncologist. Critical Reviews in Oncology/ Hematology, 99, 261-271. https://doi.org/10.1016/j.critrevonc.2015.11.017

[22] Salmen, S. and Berrueta, L. (2012) Immune Modulators of HIV Infection: The Role of Reactive Oxygen Species. Journal of Clinical \& Cellular Immunology, 3, 121. https://doi.org/10.4172/2155-9899.1000121

[23] Parameswaran, N. and Patial, S. (2010) Tumor Necrosis Factor- $\alpha$ Signaling in Macrophages. Critical Reviews $^{T x}$ in Eukaryotic Gene Expression, 20, 87-103. https://doi.org/10.1615/CritRevEukarGeneExpr.v20.i2.10

[24] Gordeuk, V.R., Ballou, S., Lozanski, G. and Brittenham, G.M. (1992) Decreased Concentrations of Tumor Necrosis Factor- $\alpha$ in Supernatants of Monocytes from Homozygotes for Hereditary Hemochromatosis. Blood, 79, 1855-1860.

[25] Xiong, S., She, H., Takeuchi, H., Han, B., Engelherd, J.F., Barton, C.H., et al. (2003) Signaling Role of Intracellular Iron in NF- $\kappa \mathrm{B}$ Activation. The Journal of Biological Chemistry, 278, 17646-17654. https://doi.org/10.1074/jbc.M210905200

[26] Lafeuillade, A. and Stevenson, M. (2011) The Search for a Cure for Persistent HIV Reservoirs. AIDS Reviews, 13, 63-66. 